\title{
High-value products from the catalytic hydrolysis of polycarbonate waste
}

\author{
Guido Grause $^{1}$, Norihiro Tsukada ${ }^{1}$, William J Hall ${ }^{2}$, Tomohito Kameda ${ }^{1}$, Paul T Williams ${ }^{2}$ \\ and Toshiaki Yoshioka ${ }^{1}$
}

The purpose of this study was to investigate the effect of additives on the recycling of waste polycarbonate (PC) by hydrolysis in a steam atmosphere. PC containing a variety of additives was obtained from waste electrical and electronic equipment (WEEE) and was hydrolyzed at 300 and $500{ }^{\circ} \mathrm{C}$ in a semibatch reactor in the presence of $\mathrm{MgO}$ and $\mathrm{CaO}$. Valuable phenolic products were obtained at high yield, with a product distribution that was strongly dependent on temperature. Bisphenol A (BPA) was the major product formed from the hydrolysis of waste $\mathrm{PC}$ at $300^{\circ} \mathrm{C}$ and was obtained in a maximum yield of $91 \%$, and degradation products of BPA such as phenol and 4-isopropenyl phenol were obtained at $500^{\circ} \mathrm{C}$. The presence of polystyrene and triphenyl phosphate in waste PC reduced the rate of the reaction by preventing steam from interacting with the surface of PC. Although pure PC was completely hydrolyzed within $15 \mathrm{~min}$, hydrolysis of waste PC took 30-60 min. However, the hydrolysis of PC in a steam atmosphere is an appropriate method for materials that cannot be treated by solvolysis.

Polymer Journal (2010) 42, 438-442; doi:10.1038/pj.2010.21; published online 31 March 2010

Keywords: additives; bisphenol-A; phenols; steam hydrolysis; WEEE waste

\section{INTRODUCTION}

Polycarbonate (PC) is a plastic used in the construction of various items such as computer housings, headlights, household devices, CDs and other applications that require excellent optical properties. The PC from such items can be collected in relatively large pieces and separated from other waste to be recycled into relatively homogeneous material. PC can be recycled using solvolysis ${ }^{1,2}$ or mechanical recycling, but neither of these methods is suitable if high concentrations of additives are present because of contamination of the recyclate. Pyrolysis of PC results in the production of high volumes of low-value char and gases. Therefore, alternative methods of recycling PC are desired.

The backbone of PC, bisphenol A (BPA), is degraded by high temperature $^{3}$ or supercritical water, ${ }^{4}$ leading to the formation of phenols. Therefore, hydrolysis, which combines both high temperature and the presence of water-based radicals, is a promising method for recycling PC that contains additives or is otherwise unsuitable for mechanical recycling. Earlier results ${ }^{5,6}$ have shown that the hydrolysis of PC in a steam atmosphere is strongly accelerated by the presence of alkali earth oxides and hydroxides, resulting in high yields of BPA at $300{ }^{\circ} \mathrm{C}$. At $500{ }^{\circ} \mathrm{C}$, phenol and 4-isopropenyl phenol (IPP) are formed by the decomposition of BPA. Studies have shown that $\mathrm{MgO}$ is more active than $\mathrm{CaO}$ in the hydrolysis of $\mathrm{PC}$, whereas differences between oxides and hydroxides were negligible.

Hydrolysis may be particularly useful for the recycling of PC from waste electrical and electronic equipment (WEEE). WEEE plastics contain various additives that reduce the flammability of the polymer.
These additives may include brominated and/or phosphorylated flame retardants and synergists such as antimony trioxide. A classic flame retardant added to PC is tetrabromobisphenol A, but triphenyl phosphate (TPP) is often used because it functions as a plasticizer and flame retardant. In addition to flame retardant additives, WEEE plastics also contain significant quantities of metals derived from fillers such as calcium carbonate and the material recovery process, in which an imperfect separation of shredded plastic and metal components leads to metal contamination in the plastic recyclate.

In this study, we investigated the use of hydrolysis for the recycling of PC from a WEEE-processing plant in the presence of magnesium and calcium catalysts. Hydrolysis products were characterized by gas chromatography-mass spectrometry and the yield of valuable products was determined.

\section{EXPERIMENTAL PROCEDURE}

Material

Waste PC was obtained as a mixture from a WEEE-processing plant in Peterborough (UK) and was derived from vacuum cleaners, telephones and other electrical devices. $\mathrm{TiO}_{2}(1.8 \mathrm{wt} \%)$, phosphorylated flame retardants/plasticizers $(6.6 \mathrm{wt} \%$ as TPP) and brominated flame retardants $(0.15 \mathrm{wt} \%$ as tetrabromobisphenol A) were identified in waste PC. In addition, aluminum $(0.1 \mathrm{wt} \%)$ was present as a contaminant in the recycling process. The PC content of the mixture was $87 \mathrm{wt} \%$ and polystyrene $(5 \mathrm{wt} \%$ ) was present as a polymer blend.

Ethanol, naphthalene, $\mathrm{CaO}$ and $\mathrm{MgO}$ (all special grade) were obtained from Kanto Kagaku (Tokyo, Japan).

${ }^{1}$ Graduate School for Environmental Studies, Tohoku University, Sendai, Japan and ${ }^{2}$ Energy and Resources Research Institute, University of Leeds, Leeds, UK Correspondence: Professor T Yoshioka, Graduate School for Environmental Studies, Tohoku University, Aramaki Aza Aoba 6-6-07 Aoba-ku, 980-8579 Sendai, Japan. E-mail: yoshioka@env.che.tohoku.ac.jp

Received 5 November 2009; revised 4 February 2010; accepted 12 February 2010; published online 31 March 2010 


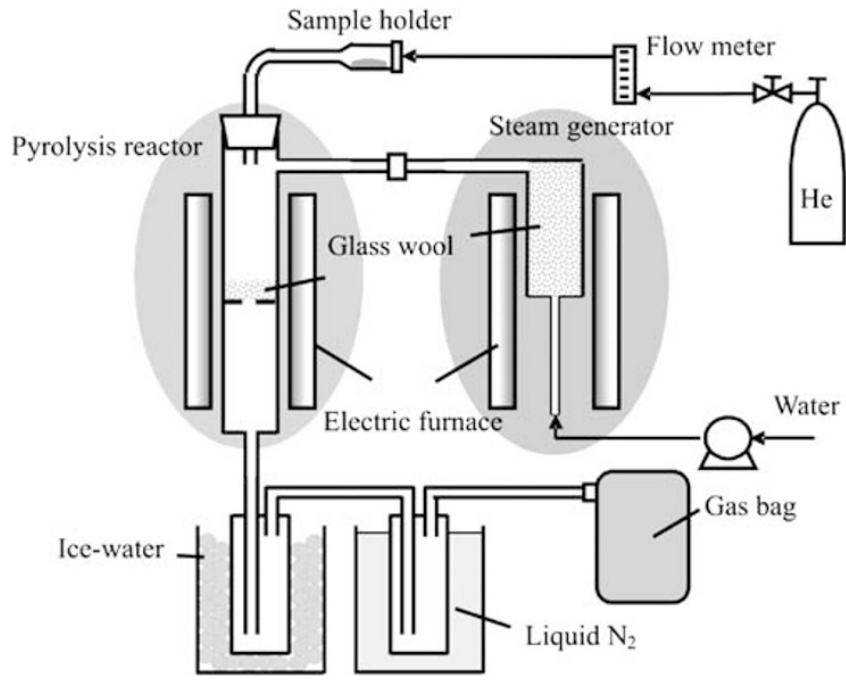

Figure 1 Experimental setup.

\section{Hydrolysis experiment}

Experiments were conducted in a semibatch fixed bed reactor (Figure 1) at temperatures between 300 and $500{ }^{\circ} \mathrm{C}$ under an $86 \mathrm{~mol} \%$ steam atmosphere in a helium carrier gas. Steam was generated at $150{ }^{\circ} \mathrm{C}$ and piped through an isolated tube into the reactor. Product oil was collected in traps cooled with iced water and liquid nitrogen, and product gas was collected in a gas bag. All experiments were repeated to verify the results.

Samples consisting of $230 \mathrm{mg}$ of PC and $180 \mathrm{mg}$ of $\mathrm{MgO}$ or $250 \mathrm{mg}$ of $\mathrm{CaO}$ (molar ratio of 1:5) were fed into a hot reactor zone over a period of $10 \mathrm{~min}$ to ensure a high sample heating rate. After reactants were fed into the reactor, the temperature was maintained at $500{ }^{\circ} \mathrm{C}$ for $20 \mathrm{~min}$ or at $300{ }^{\circ} \mathrm{C}$ for $50 \mathrm{~min}$. The reaction was assumed to be complete within the indicated time frame because longer reaction times did not lead to significantly different results. When the reaction was complete, the reactor was purged for $5 \mathrm{~min}$ with helium and the reactor and cooling traps were washed with ethanol. The collected solution was filtered through a G5 frit to remove any solid residue.

\section{Analysis}

Gas composition was analyzed by GC-TCD (GC-323, GL Science, Tokyo, Japan) with a packed column (Carboplot P7, Varian, Palo Alto, CA, USA: $\left.50{ }^{\circ} \mathrm{C}(3 \mathrm{~min}) \rightarrow 10^{\circ} \mathrm{C} \mathrm{min}^{-1} \rightarrow 150^{\circ} \mathrm{C}(3 \mathrm{~min})\right)$ and the condensed products were analyzed qualitatively by gas chromatography-mass spectrometry (GC: Hewlett Packard HP6890, MS: Hewlett Packard HP5973, Palo Alto, CA, USA) with a CP-Sil 24 MS capillary column. Quantitative analysis was performed on a GC-FID (GL-Science GC-390) with a capillary column (CP-Sil 24 CB). Response factors of the products were calculated according to the method of Jorgensen et al. ${ }^{7}$ Naphthalene was used as an internal standard. An identical temperature program $\left(50^{\circ} \mathrm{C}(5 \mathrm{~min}) \rightarrow 10^{\circ} \mathrm{C} \mathrm{min}^{-1} \rightarrow 320^{\circ} \mathrm{C}(5 \mathrm{~min})\right)$ was used in GC-FID and gas chromatography-mass spectrometry analysis. The difference between the mass of products and the mass of organic material in WEEE-PC samples was defined as the mass balance (98.1 wt\%).

WEEE-PC samples were examined by XRD and XRF to identify additives. XRD was also used to analyze residual inorganic material (Rigaku Denki Geiger-flex 2013, Rigaku Denki, Tokyo, Japan).

\section{RESULTS AND DISCUSSION}

Hydrolysis of the PC fraction of WEEE was similar to the hydrolysis of pure PC. ${ }^{6}$ However, the reaction time was significantly longer. Although the hydrolysis of pure PC was completed within $15 \mathrm{~min}$ at either temperature, hydrolysis of PC derived from WEEE took 60 and $30 \mathrm{~min}$ at 300 and $500{ }^{\circ} \mathrm{C}$, respectively. This behavior might have been caused by foreign substances in WEEE-PC samples, such as polystyrene and phosphorylated flame retardants. Although polystyrene and phosphorylated additives display different behavior during hydrolysis, the presence of either chemical may yield similar results. Flameretardant properties of phosphorous acid derivatives are a result of radical quenching in the gas phase and because of the formation of a nonvolatile thermoprotective solid layer that prohibits the formation of gases. 8,9 At $500{ }^{\circ} \mathrm{C}$, reactions between phenols and phosphates might have resulted in the formation of branched $\mathrm{PC}$, reducing the rate of hydrolysis. Polystyrene, on the other hand, was relatively unaffected by steam at temperatures below $400{ }^{\circ} \mathrm{C}$ (Figure 2). Given that PC particles shrank during hydrolysis, it can be assumed that polystyrene was enriched on the surface of PC, hindering contact with the atmosphere and reducing the rate of hydrolysis.

\section{Reaction products}

The products of WEEE-PC hydrolysis were identical to those of pure PC. Although phenol and IPP were observed as fission products of BPA at $300^{\circ} \mathrm{C}$, BPA was the major product of hydrolysis (Figure 2). The production of phenol and IPP increased at higher temperatures, whereas the amount of BPA produced by hydrolysis varied slightly between 300 and $450{ }^{\circ} \mathrm{C}$. At $500{ }^{\circ} \mathrm{C}$, fission products of BPA became dominant and phenol and IPP were obtained as the major products. Styrene was also obtained at $500{ }^{\circ} \mathrm{C}$ through pyrolysis of the polystyrene present in the sample.

Pyrolytic reactions were evidenced by changes in the appearance of product oil and residue (Figure 3). The oil changed from colorless at $300{ }^{\circ} \mathrm{C}$ to yellow at $500{ }^{\circ} \mathrm{C}$, and the color of the residue changed from slightly pink to black over the same temperature range. The color changes indicated an increase in pyrolytic degradation with increasing temperature. The slight pink color of the residue may be the result of trace amounts of iron $(0.02 \mathrm{wt} \%)$ present in the PC. No significant differences were observed between liquid samples hydrolyzed in the presence of $\mathrm{MgO}$ and $\mathrm{CaO}$.

The mass balance of the hydrolysis of WEEE-PC at 300 and $500{ }^{\circ} \mathrm{C}$ is presented in Table 1 . At $300{ }^{\circ} \mathrm{C}$, BPA was the major product and was obtained at $73 \%$ yield by weight. This is very similar to the hydrolysis of pure PC, which yielded $70 \mathrm{wt} \%$ BPA. However, less 4 - $\alpha$-cumyl phenol and more phenol and IPP were formed in WEEE-PC compared with pure PC (phenol: not detected, IPP: $1.2 \mathrm{wt} \%$, 4 - $\alpha$-cumyl phenol: $2.7 \mathrm{wt} \%) .{ }^{6} \mathrm{~A}$ negative mass balance at $300{ }^{\circ} \mathrm{C}$ using $\mathrm{MgO}$ as a catalyst was attributed to the complete hydrolysis of PC and TPP. The organic content of WEEE-PC was defined as $100 \mathrm{wt} \%$; therefore, the complete hydrolysis of WEEE content would have resulted in a product yield of $\sim 107 \mathrm{wt} \%$. After considering the theoretical yield, $\sim 5 \mathrm{wt} \%$ of material remained unaccounted for and was attributed to the concentration of styrene in WEEE-PC. Yields obtained in the presence of $\mathrm{CaO}$ were significantly lower at $300{ }^{\circ} \mathrm{C}$. The hydrolysis results of WEEE-PC and pure PC were also similar at $500^{\circ} \mathrm{C}$. Higher weight ratios of phenol and IPP and lower ratios of BPA and $4-\alpha-$ cumyl phenol were produced from WEEE-PC in the presence of $\mathrm{MgO}$. The hydrolysis of pure PC in the presence of $\mathrm{Mg}(\mathrm{OH})_{2}$ yielded 14, 21, 26 and $2.6 \mathrm{wt} \%$ of BPA, phenol, IPP and 4 - $\alpha$-cumyl phenol, respectively. ${ }^{6}$ These results revealed that the fission of BPA and degradation of IPP increased in WEEE-PC compared with pure PC.

\section{Product yields}

The yield of each product was calculated as the ratio of obtained mass (actual yield) to theoretical yield (Table 2):

$$
\text { Yield }[\%]=100 \% * \text { actual yield }[\mathrm{g} \text { or } \mathrm{mol}] / \text { theoretical yield }[\mathrm{g} \text { or mol }]
$$




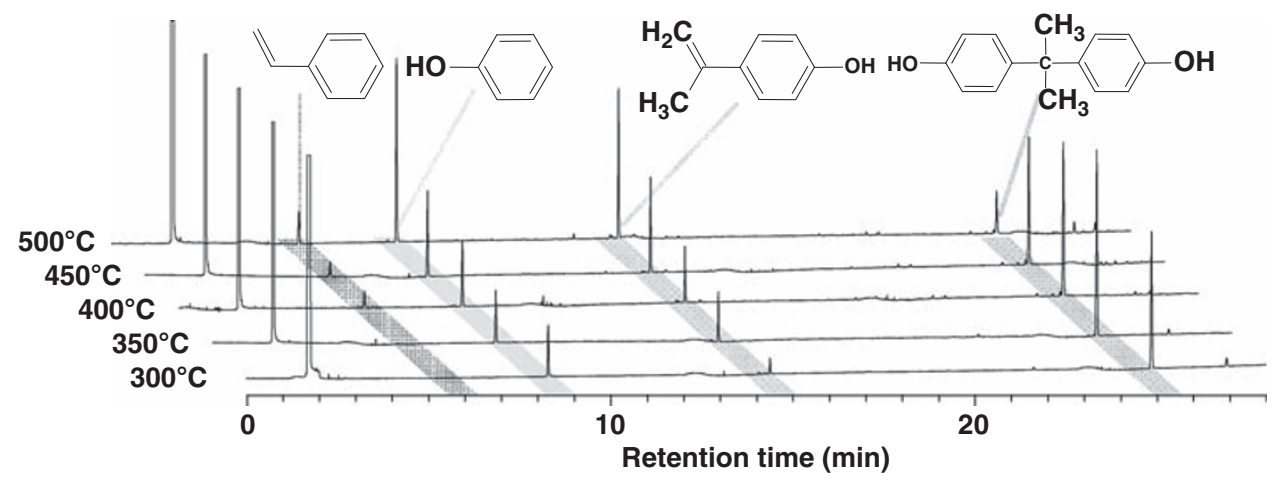

Figure 2 GC-FID of the liquid products of WEEE-PC hydrolysis in the presence of MgO. Styrene, phenol, IPP and BPA peaks are underlined in gray.
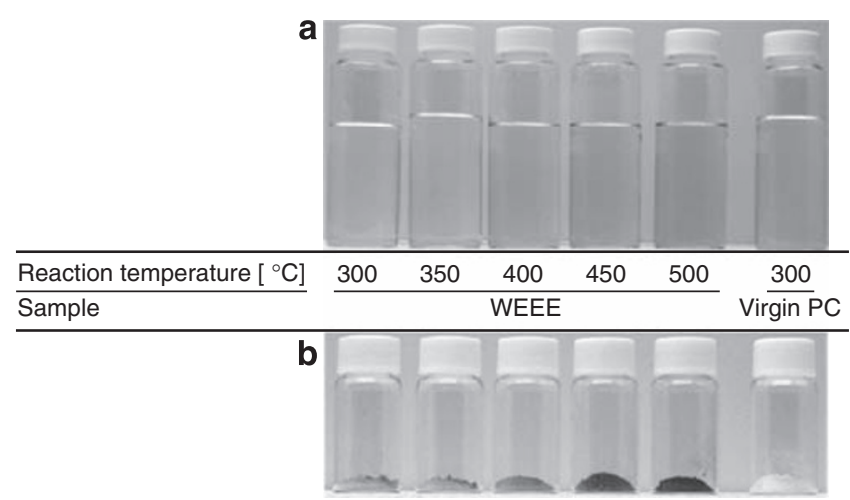

Figure 3 Photographs of products obtained at different temperatures in the presence of MgO: (a) oil (b) residue.

Table 1 Mass balance of the hydrolysis of waste electrical and electronic equipment given in wt\%

\begin{tabular}{|c|c|c|c|c|}
\hline & \multicolumn{2}{|c|}{$300^{\circ} \mathrm{C}$} & \multicolumn{2}{|c|}{$500^{\circ} \mathrm{C}$} \\
\hline & $\mathrm{MgO}$ & $\mathrm{CaO}$ & $\mathrm{MgO}$ & $\mathrm{CaO}$ \\
\hline & $60 \mathrm{~min}$ & $60 \mathrm{~min}$ & $30 \mathrm{~min}$ & $30 \mathrm{mir}$ \\
\hline Gases & 12 & 5.8 & 14 & 4.9 \\
\hline Methane & - & - & 0.06 & 0.22 \\
\hline Carbon dioxide & 12 & 5.8 & 14 & 4.6 \\
\hline Ethene & - & - & 0.04 & 0.05 \\
\hline Liquids and solids & 89 & 53 & 68 & 57 \\
\hline Styrene & - & - & 4.5 & 3.5 \\
\hline Phenol & 9.2 & 4.5 & 29 & 25 \\
\hline Isopropyl phenol & - & - & 0.83 & 0.94 \\
\hline Isopropenyl phenol & 5.6 & 1.0 & 20 & 17 \\
\hline 4- $\alpha$-cumyl phenol & 0.28 & 0.4 & 0.35 & 0.42 \\
\hline Bisphenol A & 73 & 47 & 7.7 & 7.8 \\
\hline Others & 1.8 & 0.6 & 5.9 & 2.4 \\
\hline Balance & -1.9 & 41 & 18 & 39 \\
\hline
\end{tabular}

The theoretical yield of BPA was defined as the mass of BPA achieved from the complete hydrolysis of PC without any further reaction (Scheme 1). The theoretical yield of IPP was defined as the mass of
Table 2 Yields of BPA, phenol and IPP, obtained from the hydrolysis of WEEE

\begin{tabular}{lcccccc}
\hline & \multicolumn{2}{c}{$300^{\circ} \mathrm{C}$} & & \multicolumn{2}{c}{$500^{\circ} \mathrm{C}$} \\
\cline { 2 - 3 } \cline { 5 - 6 } & MgO & CaO & & MgO & CaO \\
& $60 \mathrm{~min}$ & $60 \mathrm{~min}$ & & $30 \mathrm{~min}$ & $30 \mathrm{~min}$ \\
\hline BPA (\%) & 91 & 59 & & 10 & 10 \\
Phenol (\%) & 24 & 11 & & 77 & 63 \\
IPP (\%) & 12 & 2 & & 44 & 39 \\
Phenol from BPA & 12 & 2 & & 53 & 43.5 \\
Phenol from TPP & 12 & 9 & & 15 & 15 \\
Phenol from IPP & 0 & 0 & & 9 & 4.5 \\
Lost BPA yield & -3 & 39 & & 37 & 46.5 \\
\hline
\end{tabular}

Abbreviations: BPA, bisphenol A; IPP, 4-isopropenyl phenol; TPP, triphenyl phosphate; WEEE, waste electrical and electronic equipment.

IPP obtained after the complete fission of BPA without any further degradation.

To calculate the yield of phenol, it was assumed that phenol was produced by the fission of BPA and hydrolysis of TPP. The degradation of IPP also results in the formation of phenol but was not considered in the calculation. It was assumed that WEEE-PC contained $87 \mathrm{PC}$ and $6.6 \mathrm{wt} \%$ TPP; however, the amount of TPP was only an estimate based on the phosphorous content, obtained by elemental analysis. Because other compounds containing phosphorus may have been present in WEEE-PC, the actual yield of phenol might be slightly higher.

BPA was recovered in 91\% yield from the hydrolysis of WEEE-PC at $300{ }^{\circ} \mathrm{C}$ in the presence of $\mathrm{MgO}$. The yields of phenol and IPP were 24 and $12 \%$, respectively. A theoretical yield of approximately $15 \%$ is achieved on complete hydrolysis of TPP. Under the assumption that IPP does not undergo further degradation to produce phenol, the theoretical yield of IPP and phenol should be $12 \%$. Therefore, the additional phenol produced by the reaction was assigned to the hydrolysis of TPP. The total yield of BPA and IPP was 103\%, which may be attributed to analytical inaccuracies. On the basis of these results, it can be assumed that the reaction in the presence of $\mathrm{MgO}$ led to the complete hydrolysis of PC. On the other hand, less product was obtained by the hydrolysis of WEEE-PC in the presence of $\mathrm{CaO}$. Using the aforementioned analysis, $2 \%$ phenol was obtained from the fission of BPA and 9\% from the hydrolysis of TPP. Adding the BPA yield (59\%) and the IPP yield (2\%) shows that 39\% of PC was not 
a<smiles>COC(=O)Oc1ccc(C(C)(C)c2ccc(C(C)(C)C)cc2)cc1</smiles>

PC $-\mathrm{CO}_{2} \downarrow+\mathrm{H}_{2} \mathrm{O}$<smiles>CC(C)(c1ccc(O)cc1)c1ccc(O)cc1</smiles>
BPA<smiles>CC(=Cc1cccc(O)c1)c1ccc(O)cc1</smiles>
Phenol

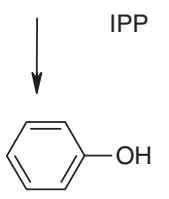

Phenol

Scheme 1 Formation of (a) bisphenol-A (BPA), phenol and 4-isopropenyl phenol (IPP) from polycarbonate (PC) and (b) phenol from triphenyl phosphate (TPP).

hydrolyzed under the reaction conditions, nor did it undergo competitive reactions.

In the presence of $\mathrm{MgO}$ at $500{ }^{\circ} \mathrm{C}, \mathrm{BPA}$ was degraded mainly to phenol and IPP, in yields of 73 and $42 \%$, respectively. The total theoretical yield of IPP and phenol is $>200 \%$. Under the assumption that TPP was completely hydrolyzed under the reaction conditions, the difference between the amounts of phenol obtained from PC and IPP was $18 \%$, suggesting that $9 \%$ of IPP was degraded. Thus, $53 \%$ of PC was degraded to phenol and IPP, $10 \%$ led to the production of BPA and $37 \%$ underwent competitive reactions and was obtained as residue. The differences between $\mathrm{MgO}$ - and $\mathrm{CaO}$-catalyzed reactions were less significant at $500{ }^{\circ} \mathrm{C}$ than at $300{ }^{\circ} \mathrm{C}$.

WEEE-PC required longer reaction times because the rate of hydrolysis was reduced compared with pure PC. Accordingly, more fission of BPA and IPP occurred during the hydrolysis of WEEE-PC, resulting in an increased yield of phenol.

\section{Residue analysis}

A critical factor in feedstock recycling is the presence of residue remaining after the reaction. Residue, which is considered waste, is obtained at the expense of the desired product. It requires expensive removal from the reactor and reduces the activity of the catalyst. The amount of residue produced by hydrolysis of WEEE-PC was not accessible; therefore, mass lost during the reaction was considered residue. At $300^{\circ} \mathrm{C}$, in the presence of $\mathrm{MgO}$, the mass balance was negative, indicating that complete hydrolysis of PC had occurred (Table 1). As the mass balance was calculated on the basis of WEEE-PC, a negative amount of residual material indicated that the weight of the products was higher than that of the input material. The increase in mass may be due to side reactions with water during the hydrolysis of PC. In addition, polystyrene has a high degradation temperature and remained unaffected in the residue. Higher temperatures led to an increase in residual material because condensation reactions competed with the hydrolysis of PC. During condensation, aromatic structures such as diphenylether, xanthone, dibenzofuran

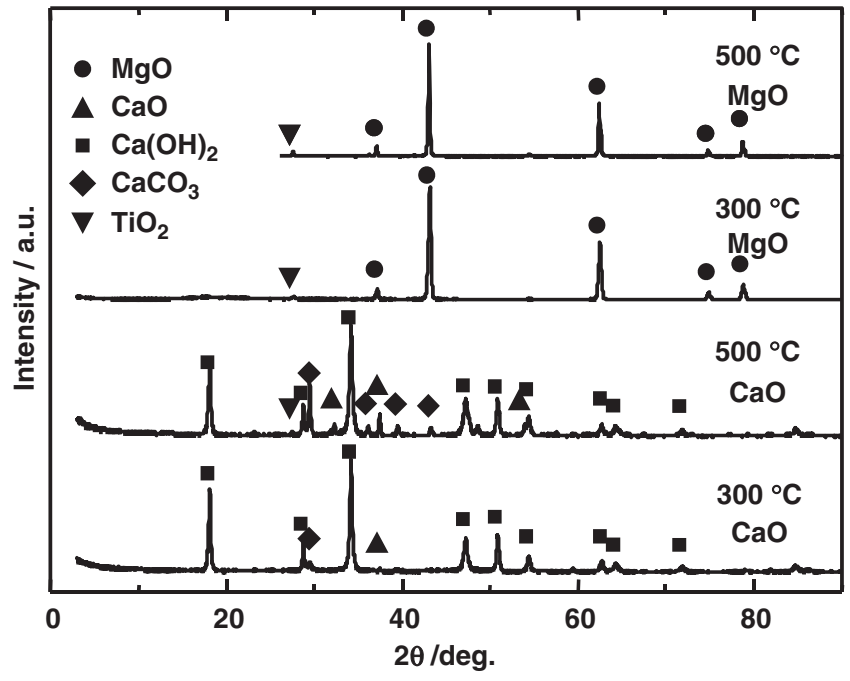

Figure 4 XRDs of the residue after hydrolysis of WEEE-PC.

and fluorenone were formed from neighboring PC units. ${ }^{10,11}$ These structures are not valuable products and function as precursors for char formation. The production of condensed aromatic compounds is supported by the change in residue color from slightly pink at $300^{\circ} \mathrm{C}$ to black at $500{ }^{\circ} \mathrm{C}$ (Figure 3b), indicating the presence of carbon.

One important reason for the enhanced formation of residue in the presence of $\mathrm{CaO}$ is the absorption of $\mathrm{CO}_{2}$. $\mathrm{MgO}$ does not form $\mathrm{Mg}(\mathrm{OH})_{2}$ or $\mathrm{MgCO}_{3}$ above $300^{\circ} \mathrm{C}$, and no changes in the catalyst were observed using XRD (Figure 4 ). On the contrary, $\mathrm{CaO}$ forms mainly $\mathrm{Ca}(\mathrm{OH})_{2}$ under a steam atmosphere at $500{ }^{\circ} \mathrm{C}$. However, small amounts of $\mathrm{CaO}$ and $\mathrm{CaCO}_{3}$ were found at $500^{\circ} \mathrm{C}$. $\mathrm{TiO}_{2}$ was also present in all samples. Details of the degradation mechanism were presented in a previous report. ${ }^{6}$

\section{CONCLUSION}

Hydrolysis of the PC fraction of WEEE is not significantly different from hydrolysis of pure PC. The presence of $\mathrm{MgO}$ changes the mechanism of the reaction and is a more active catalyst than $\mathrm{CaO}$. Styrene and TPP in impure PC causes a reduction in the reaction rate; however, styrene does not degrade at $300{ }^{\circ} \mathrm{C}$ and remains in the residue. On the other hand, styrene undergoes pyrolysis at $500{ }^{\circ} \mathrm{C}$. TPP forms a protective layer at $500^{\circ} \mathrm{C}$, and both styrene and TPP may cover the surface of PC particles during hydrolysis and prevent steam from interacting with PC.

PC is completely hydrolyzed at $300{ }^{\circ} \mathrm{C}$, resulting in a high yield of BPA (91\%), phenol and IPP byproducts. TPP was a major source of phenol at $300{ }^{\circ} \mathrm{C}$. Alternatively, BPA decomposes at $500{ }^{\circ} \mathrm{C}$ and phenol and IPP were obtained as the major products. Pyrolysis at $500{ }^{\circ} \mathrm{C}$ leads to an enhanced formation of residue.

Inorganic materials such as fillers, fire retardants and other additives are often present in waste PC; dirt is another common impurity. As these materials are virtually insoluble in solvents, sludge is formed during solvolysis. The separation of sludge from solvent is a complicated problem for many waste materials. In hydrolysis, inorganic solid impurities remain with the catalyst and can be separated from organic products. After hydrolysis, the catalyst can be used in construction materials if toxic substances are not present. However, if valuable materials have accumulated in the residue, it may be necessary to reprocess the catalyst. The results of this study revealed that hydrolysis can transform PC contaminated with foreign materials such as fillers, 
flame retardants, copolymers and blends into valuable products. Highly filled, contaminated or blended materials cannot be processed by solvolysis because extraneous substances might cause competitive reactions or prevent the separation of products. In these cases, hydrolysis is an adequate alternative to solvolysis.

\section{ACKNOWLEDGEMENTS}

This research was partially supported by the Ministry of Education, Science, Sports, and Culture through Grant-in-Aid for Scientific Research (A), 21241018, 2009.

1 Pinero, R., Garcia, J. \& Cocero, M. J. Chemical recycling of polycarbonate in a semicontinuous lab-plant. A green route with methanol and methanol-water mixtures. Green Chem. 7, 380-387 (2005).

$2 \mathrm{Hu}, \mathrm{L} .-\mathrm{C} ., \mathrm{Oku}, \mathrm{A} . \&$ Yamada, E. Alkali-catalyzed methanolysis of polycarbonate. A study on recycling of bisphenol A and dimethyl carbonate. Polym. 39, 3841-3845 (1998).
3 Hunter, S. E. \& Savage, P. E. Kinetics and mechanism of p-isopropenylphenol synthesis via hydrothermal cleavage of bisphenol A. J. Org. Chem. 69, 4724-4731 (2004).

4 Adschiri, T., Shibata, R. \& Arai, K. Phenol recovery by bisphenol-A (BPA) tar hydrolysis in supercritical water. Sekiyu Gakkaishi 40, 291-297 (1997).

5 Yoshioka, T., Sugawara, K., Mizoguchi, T. \& Okuwaki, A. Chemical recycling of polycarbonate to raw materials by thermal decomposition with calcium hydroxide/ steam. Chem. Lett. 34, 282-283 (2005).

6 Grause, G., Sugawara, K., Mizoguchi, T. \& Yoshioka, T. Pyrolytic hydrolysis of polycarbonate in the presence of earth-alkali oxides and hydroxides. Polym. Degrad. Stab. 94, 1119-1124 (2009).

7 Jorgensen, A. D., Picel, K. C. \& Stamoudis, V. C. Prediction of gas chromatography flame ionization detector response factors from molecular structures. Anal. Chem. 62, 683-689 (1990).

8 Jang, B. N. \& Wilkie, C. A. The effects of triphenylphosphate and recorcinolbis(diphenylphosphate) on the thermal degradation of polycarbonate in air. Thermochim. Acta 433, 1-12 (2005).

9 Bozi, J., Czégény, Z., Mészáros, E. \& Blazsó, M. Thermal decomposition of flame retarded polycarbonates. J. Anal. Appl. Pyrolysis 79, 337-345 (2007).

10 Puglisi, C., Samperi, F., Carroccio, S. \& Montaudo, G. MALDI-TOF investigation of polymer degradation. Pyrolysis of poly(bisphenol A carbonate). Macromolecules 32, 8821-8828 (1999).

11 Puglisi, C., Sturiale, L. \& Montaudo, G. Thermal decomposition processes in aromatic polycarbonates investigated by mass spectrometry. Macromolecules 32, 2194-2203 (1999). 